\title{
Adenylyl cyclase 8 is central to glucagon-like peptide 1 signalling and effects of chronically elevated glucose in rat and human pancreatic beta cells
}

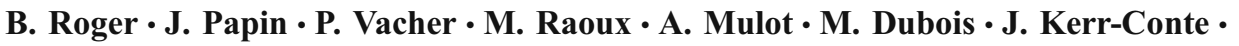 \\ B. H. Voy • F. Pattou • G. Charpentier • J.-C. Jonas • N. Moustaïd-Moussa • J. Lang
}

Received: 14 July 2010 / Accepted: 8 September 2010 /Published online: 3 November 2010

(C) Springer-Verlag 2010

\begin{abstract}
Aims/hypothesis Glucose and incretins regulate beta cell function, gene expression and insulin exocytosis via calcium and cAMP. Prolonged exposure to elevated glucose (also termed glucotoxicity) disturbs calcium homeostasis, but little is known about cAMP signalling. We therefore investigated long-term effects of glucose on this pathway with special regard to the incretin glucagon-like peptide 1 (GLP-1).

Methods We exposed INS-1E cells and rat or human islets to different levels of glucose for 3 days and determined functional responses in terms of second messengers (cAMP, $\mathrm{Ca}^{2+}$ ), transcription profiles, activation of cAMP-responsive element (CRE) and secretion by measuring membrane capacitance. Moreover, we modulated directly the abundance of a calcium-sensitive adenylyl cyclase (ADCY8) and GLP-1 receptor (GLP1R).
\end{abstract}

B. Roger and J. Papin contributed equally to this study.

Electronic supplementary material The online version of this article (doi:10.1007/s00125-010-1955-x) contains supplementary material, which is available to authorised users.

\footnotetext{
B. Roger $\cdot$ J. Papin $\cdot$ M. Raoux $\cdot$ A. Mulot $\cdot$ M. Dubois $\cdot$

G. Charpentier $\cdot$ J. Lang $(\square)$

Université de Bordeaux 1,

Institut Européen de Chimie et Biologie,

UMR CNRS 5248, 2 Av Robert Escarpit,

33607 Pessac, France

e-mail: j.lang@iecb.u-bordeaux.fr

P. Vacher

Institut Bergonié, Université de Bordeaux 2, INSERM U916,

Bordeaux, France
}

J. Kerr-Conte $\cdot$ F. Pattou

Biotherapies for Diabetes, Université Lille-Nord de France,

INSERM U859,

Lille, France
Results GLP-1- or forskolin-mediated increases in cytosolic calcium, cAMP-levels or insulin secretion were largely reduced in INS-1E cells cultured at elevated glucose $(>5.5 \mathrm{mmol} / \mathrm{l})$. Statistical analysis of transcription profiles identified cAMP pathways as major targets regulated by glucose. Quantitative PCR confirmed these findings and unravelled marked downregulation of the calcium-sensitive adenylyl cyclase ADCY8 also in rat and in human islets. Re-expression of ADCY8, but not of the GLP1R, recovered GLP-1 signalling in glucotoxicity in INS-1E cells and in rat islets. Moreover, knockdown of this adenylyl cyclase showed that GLP-1-induced cAMP generation, calcium signalling, activation of the downstream target CRE and direct amplification of exocytosis by cAMP-raising agents (evaluated by capacitance measurement) proceeds via ADCY8.

Conclusions/interpretation cAMP-mediated pathways are modelled by glucose, and downregulation of the calcium-

B. H. Voy $\cdot$ N. Moustaïd-Moussa

Obesity Research Center and Department of Animal Science,

University of Tennessee,

Knoxville, TN, USA

J.-C. Jonas

Secteur des Sciences de la Santé,

Institut de Recherche Expérimentale et Clinique,

Pôle de Recherche en Endocrinologie, Diabète et Nutrition,

Université Catholique de Louvain,

Brussels, Belgium

Present Address:

M. Dubois

UFR de Pharmacie, Université de Bordeaux 2,

Bordeaux, France 
sensitive ADCY8 plays a central role herein, including signalling via the GLP1R.

Keywords ADCY8 - Adenylate cyclase - Calcium · CRE Cyclic AMP · Exocytosis · Islets · GLP-1 · Glucotoxicity · Incretins

\begin{tabular}{|c|c|}
\hline Abbreviations & \\
\hline $\mathrm{ADCY}$ & Adenylyl cyclase \\
\hline AKAP & A-kinase anchoring protein \\
\hline$\left[\mathrm{Ca}^{2+}\right]_{\mathrm{i}}$ & Cytosolic free calcium \\
\hline CRE & cAMP-responsive element \\
\hline CREM/ICER & $\begin{array}{l}\text { cAMP-responsive element modulator/ } \\
\text { inducible cAMP early repressor }\end{array}$ \\
\hline eGFP & Enhanced green fluorescent protein \\
\hline EPAC & $\begin{array}{l}\text { Exchange protein directly activated by } \\
\text { cAMP }\end{array}$ \\
\hline GLP-1 & Glucagon-like peptide 1 \\
\hline GLP1R & Glucagon-like peptide 1 receptor \\
\hline GPCR & G protein coupled receptor \\
\hline PDE & Phosphodiesterase \\
\hline PKA & Protein kinase A \\
\hline shRNA & Short hairpin RNA \\
\hline
\end{tabular}

\section{Introduction}

Glucose stimulates insulin secretion and modulates gene expression by regulating levels of calcium and cAMP in pancreatic beta cells [1]. Prolonged exposure to elevated levels of glucose, termed glucotoxicity [2], reduces glucose detection, modifies glucose metabolism as well as calcium handling and induces cellular stress [3]. Moreover, increased levels of glucose are directly correlated to decreased efficiency of incretin hormones, such as glucagon-like peptide 1 (GLP-1), on insulin secretion [4, 5].

The stimulatory action of incretins contributes considerably to physiological insulin secretion in beta cells [6]. Recognition of GLP-1 by its cognate receptor activates a classical signalling cascade via $\mathrm{G}_{\mathrm{s}}$ and adenylyl cyclases, thus increasing cellular levels of cAMP and activating the effectors protein kinase A (PKA) and exchange protein directly activated by cAMP (EPAC [6]. GLP-1 facilitates membrane depolarisation through ATP-dependent potassium channels $\left(\mathrm{K}_{\mathrm{ATP}}\right)$ in a PKA-and EPAC-dependent manner, antagonises voltage-dependent $\mathrm{K}^{+}$channels via PKA and transactivates the epidermal growth factor receptor [7-9]. The ensuing $\mathrm{Ca}^{2+}$ influx is further enhanced by PKA-dependent phosphorylation of voltage-dependent calcium channels and mobilisation of calcium from stores $[10,11]$. Whereas calcium constitutes the sole trigger of insulin exocytosis $[1,12]$, cAMP amplifies exocytosis and is required for the full physiological response [13]. In addition, GLP-1 also acts as a growth factor as well as a differentiation factor, and activation of the cAMP-response element (CRE) via calcium- and cAMP-dependent pathways is essential for glucose homeostasis and beta cell survival [14].

Prolonged exposure to elevated levels of glucose alters calcium handling in a cAMP-dependent manner $[15,16]$. As the incretin GLP-1 exerts most of its effects through these second messengers and its efficacy is partially lost in type 2 diabetes, we used this hormone to investigate the interplay between cAMP and calcium under exposure to normal and chronically elevated glucose levels to identify underlying changes in signal transduction and gene expression.

\section{Methods}

Materials The following antibodies were used: anti-actin (Abcam, Cambridge, UK), anti-CD8 (DAKO, Glostrup, Denmark), anti-adenylyl cyclase (ADCY8), anti-glucagonlike peptide 1 (GLP1R) and anti-synaptotagmin IV (SYT4) (Santa Cruz Biotechnology, Santa Cruz, CA, USA). Antibodies against enhanced green fluorescent protein (eGFP), cAMP-responsive element modulator/inducible cAMP early repressor (CREM/ICER), A kinase (PRKA) anchor protein 12 (AKAP12) and calcium and DAG-regulated guanine nucleotide exchange factor (Caldag-GEFI [also known as RASGRP2]) were generously donated by $\mathrm{M}$. Rout (Rockefeller University, New York, NY, USA), J. Miano (University of Rochester, Rochester, NY, USA), L. Gao and I. Gelman (Roswell Park Cancer Institute, Buffalo, NY, USA) and A. Graybiel (MIT, Cambridge, MA, USA), respectively. Plasmids encoding ADCY8, ADCY8-eGFP and myc-GLP1R were generously donated by D. Cooper (University of Cambridge, UK) and A. Bisello (University of Pittsburgh, PA, USA). Plasmids encoding control short hairpin RNA (shRNA) or shRNA directed against ADCY8 were from SABiosciences (Frederick, MD, USA), the plasmid encoding human growth hormone (hGH) has been described $[16,17]$. CD8-eGFP was obtained by replacing the cytosolic domain of CD8 with eGFP.

Preparation of islets, cell culture, secretion assays, immunofluorescence, determination of CAMP and CREactivation Rat islets or human donor islets were obtained and cultured as described [18, 19] and approved by the ethics committee. For calcium imaging, rat islet cells were seeded on polylysine-coated glass coverslips $(6,000 /$ coverslip, $25 \mathrm{~mm}$ diameter) and precultured for 4 days at $11 \mathrm{mmol} / \mathrm{l}$ glucose before transfection with lipofectamine. Cells were cultured subsequently for $72 \mathrm{~h}$ at indicated glucose concentration as described [19]. 
INS-1E cells were generously provided by P. Maechler and C. B. Wollheim (Université de Genève, Switzerland). Cell culture, transfections, secretion assays and immunocytochemistry were as published $[16,17]$. Glucose pretreatments were conducted in the presence of $10 \%$ FCS [16]. For determination of cAMP, cells were exposed for $30 \mathrm{~min}$ to indicated agents and cellular cAMP was measured by ELISA (Correlate-EIA; Assay Designs, Ann Harbor, MI, USA). Activation of CRE was determined using pCRELUC (Invitrogen, Carlsbad, CA, USA) and peGFP for normalisation, luciferase was measured using the Luciferase Assay System (Promega, Madison, WI, USA).

Sorting of co-transfected INS-1E cells Cells were cotransfected with a plasmid encoding the extracellular/ transmembrane domain of CD8 linked to eGFP and the plasmid of interest. After $72 \mathrm{~h}$ of culture, cells were detached in $\mathrm{PBS} / 10 \mathrm{mmol} / 1 \mathrm{EDTA}$ at $37^{\circ} \mathrm{C}$, centrifuged, resuspended in ice-cold PBS/2 mmol/l EDTA and incubated at $4^{\circ} \mathrm{C}$ for 30 min with magnetic beads coated with antiCD8 antibodies (Invitrogen). CD8-expressing cells were recovered using a magnet and washed three times in cold PBS/EDTA $2 \mathrm{mmol} / \mathrm{l}$ before assays.

Protein production and quantitative PCR Proteins resolved by SDS-PAGE were immunoblotted as described [16]. Quantitative PCR was performed as published [16]. The cycle threshold $\left(\mathrm{C}_{\mathrm{t}}\right)$ value of each gene was normalised against household genes (EFIa [also known as EF1A] and $\beta$-actin, INS-1E cells; TBP, rat islets; GUSB, human islets) and the relative expression levels calculated using the comparative $\left(2^{-\Delta \Delta \mathrm{C}_{\mathrm{t}}}\right)$ method. Threshold cycles ranged from 14 to 30 and primers used are detailed in Electronic supplementary material (ESM) Table 1. Statistics were performed on $\mathrm{C}_{t}$ values normalised for household genes.

Oligonucleotide microarray Total RNA was extracted (RNAeasy; Qiagen, France) and used to synthesise labelled cRNAs for hybridisation of rat expression arrays (230 2.0; Affymetrix, Santa Clara, CA, USA). Data were analysed with Arraystar v3.0 (DNASTAR, Madison, WI, USA) and PLIER (Quantile/Perfect Match-Mismatch) used for normalisation. Of 31,099 transcripts, 22,084 were reliably detected on arrays in at least one glucose concentration at a mean signal intensity $>5$ ( $\log 2$ value) and selected for further analysis; 3,614 transcripts showed differences among at least two conditions (ANOVA, $p<0.02$ ), and finally 2,064 transcripts were retained with a fold change $>1.5$ and a false discovery rate $<0.02$ in at least one comparison (see ESM Table 2). Pathway analysis was performed using Ingenuity Pathways Analysis (Ingenuity Systems, Redwood City, CA, USA).
Microfluorimetry and electrophysiology Microfluorimetry was performed as described [16, 17]. Electrophysiological recordings were performed by the whole-cell configuration of the patch clamp technique using an EPC-9 amplifier (HEKA, Lambrecht, Germany). Data were acquired and analysed with Patchmaster/Fitmaster (v2.35, HEKA). Patch pipettes pulled from borosilicate glass capillaries had tip resistances of 2-4 $\mathrm{M} \Omega$ when filled with intracellular solutions. The zero-current potential was adjusted in the bath. The composition of the intracellular pipette solution was (in mmol/l): $\mathrm{KCl} 135 ; \mathrm{NaCl} 10 ; \mathrm{MgCl}_{2} 1 ; \mathrm{CaCl}_{2}$ 9, EGTA 10, Mg-ATP 3; HEPES 5; pH adjusted to 7.1 with $\mathrm{KOH}$. The extracellular medium was (in $\mathrm{mmol} / \mathrm{l}$ ): $\mathrm{NaCl}$ 138; $\mathrm{KCl} 5.6 ; \mathrm{MgCl}_{2}$ 1.2; $\mathrm{CaCl}_{2}$ 2.6, HEPES 5; glucose
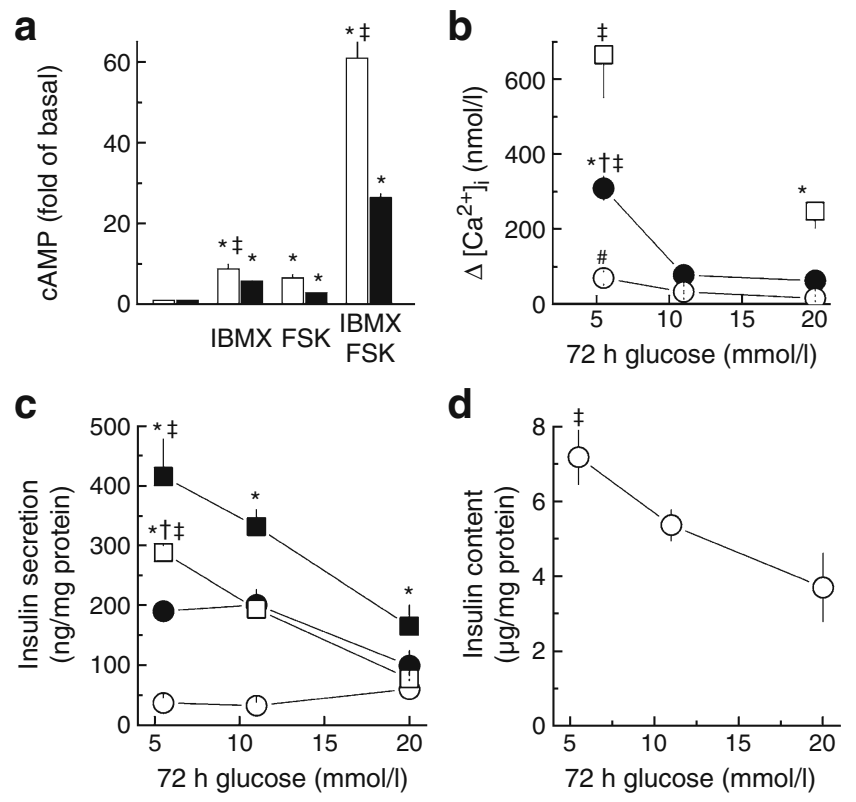

Fig. 1 Prolonged exposure to elevated concentrations of glucose diminishes GLP-1 or forskolin-induced raises in cAMP generation, cytosolic calcium and insulin secretion in INS-1E beta cells. a Generation of cAMP in cells cultured at 5.5 (white bars) or at $20 \mathrm{mmol} / \mathrm{l}$ glucose (black bars) for $72 \mathrm{~h}$ and subsequently exposed to $5.5 \mathrm{mmol} / \mathrm{l}$ glucose in the absence or presence of forskolin (FSK, $1 \mu \mathrm{mol} / 1)$ and/or IBMX $(100 \mu \mathrm{mol} / 1) ; n=4$. b Increases in cytosolic calcium $\left(\left[\mathrm{Ca}^{2+}\right]_{\mathrm{i}}\right.$ ) evoked by glucose (white circles) $10 \mathrm{nmol} / 1 \mathrm{GLP}-1$ (black circles) or FSK (white squares) in cells cultured at indicated glucose concentrations for $72 \mathrm{~h}$. Note that cells were kept at 5.5 (G5.5) or $15 \mathrm{mmol} / 1$ glucose (G15) for $30 \mathrm{~min}$ before the addition of GLP-1 or FSK, which ensured a stable baseline (see also Figs 5, 6 and 7); $n=$ 15-77. c Insulin secretion was stimulated for $30 \mathrm{~min}$ by either $15 \mathrm{mmol} / \mathrm{l}$ glucose alone (black circles), or $15 \mathrm{mmol} / 1$ glucose in the presence of $10 \mathrm{nmol} / 1 \mathrm{GLP}-1$ (white squares) or $1 \mu \mathrm{mol} / \mathrm{l} \mathrm{FSK}$ (black squares). Basal secretion $(2.8 \mathrm{mmol} / \mathrm{l}$ glucose $)$ is given by white circles. Data are normalised for total protein at the respective glucose concentration; $n=6-11$. d Insulin content after $72 \mathrm{~h}$ culture at different glucose levels; $n=11$. Statistics (a-d): $* p<0.05$ compared with the absence of FSK or of IBMX (a) with GLP-1 alone (b) or with G15 alone (c); ${ }^{\dagger} p<0.05$ compared with cells cultured at G11; ${ }^{\star} p<0.05$ compared with cells cultured at G20 
5.5 , pH 7.4 with $\mathrm{NaOH}$. Holding potential was $-70 \mathrm{mV}$ to prevent activation of voltage-dependent depolarising channels. Increases of cell capacitance were determined using a sine + DC protocol of the LockIn extension of the HEKA software (40 mV peak-to-peak, 1,250 Hz). Exocytosis was triggered by either iterative $200 \mathrm{~ms}$ depolarising steps from a holding potential at -70 to $0 \mathrm{mV}$ or by intracellular dialysis of the calcium containing solution $(1.5 \mu \mathrm{mol} / \mathrm{l})$ [20] from the micropipette. Changes of cell capacitance were measured during the first minutes following the establishment of the whole-cell configuration. Curve fittings were done in ORIGIN v8 (OriginLab Corporation, Northampton, MA, USA).

Statistics Experiments were replicated at least three times. Unless otherwise stated, data are given as mean \pm SEM and groups were compared using ANOVA with Bonferroni as post hoc test.

\section{Results}

Prolonged exposure to elevated glucose blunts cAMP-mediated effects Dynamics of cAMP and cytosolic calcium are linked [21], contributing both to insulin secretion and gene expression [12, 13]. We first examined whether prolonged exposure to glucose alters the generation of cAMP in INS-1E cells (Fig. 1a). Note that the conditions used induced only a minor increase in apoptosis in line with previous observations [16]. The response to forskolin, a general activator of adenylyl cyclases, or IBMX, a general inhibitor of phosphodiesterases, was reduced by $60 \%$ and $30 \%$, respectively, in cells cultured for 3 days at $20 \mathrm{mmol} / \mathrm{l}$ glucose (G20). When both agents were added together, cAMP accumulation was again reduced by two-thirds in cells cultured at G20. This suggests that the decrease in stimulation observed

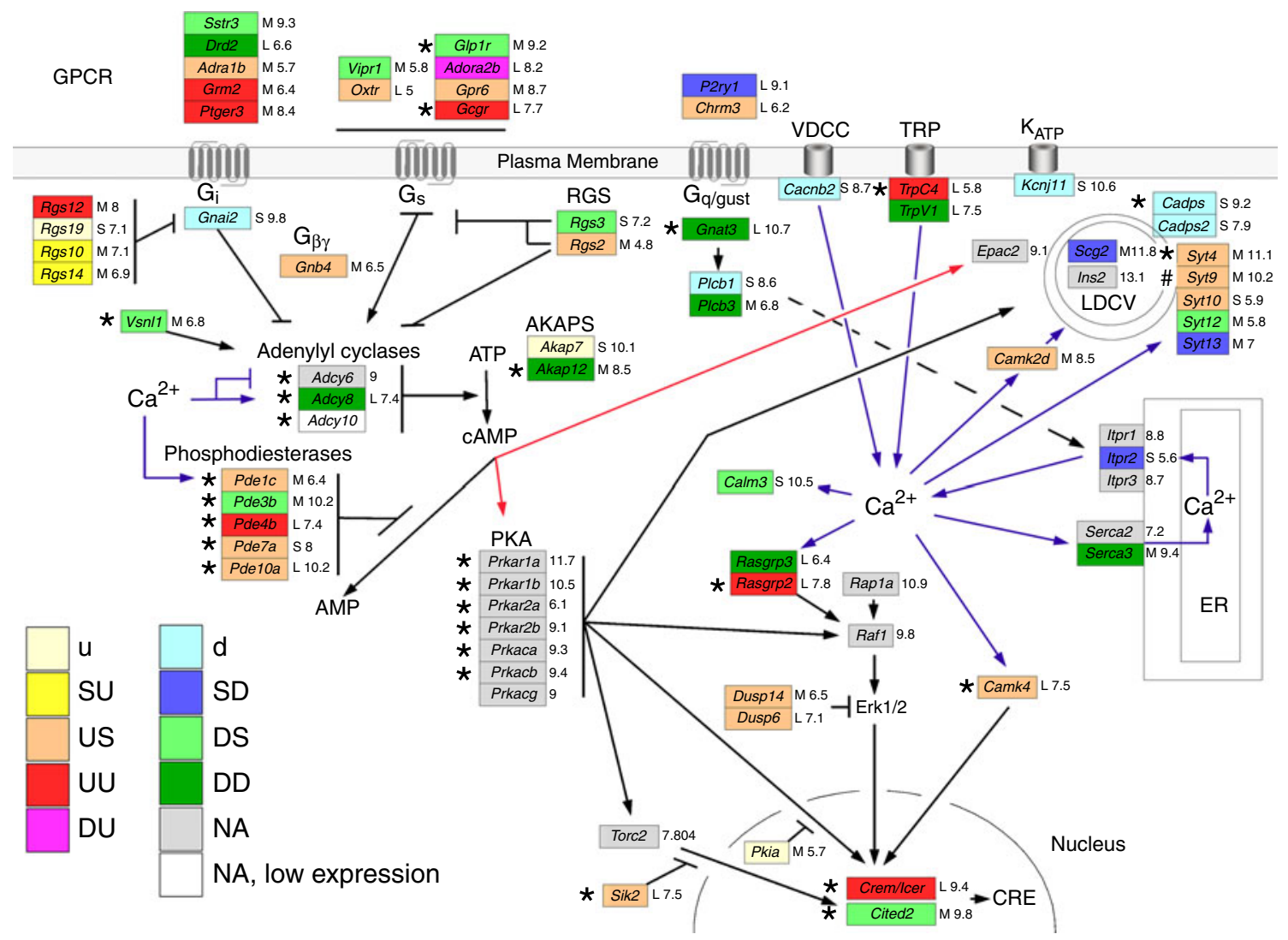

Fig. 2 Glucose-induced changes in the mRNA levels of genes involved in cAMP- and calcium-mediated pathways. A biological map was created according to analysis of canonical pathways by INGENUITY. Genes involved in selected signalling pathways were coloured according to the cluster to which they belong using GenMAPP 2.0 (see also ESM Table 1). u or d, up- or downregulated between 5.5 and $20 \mathrm{mmol} / 1$ glucose (fold change $<1.5$ ); S, U or $\mathrm{D}$, stable, up- or downregulated between two glucose concentrations (fold change $>1.5$; $\mathrm{S}$, no change), the combination indicates thus the profile between 5.5 and 11 and between 11 and $20 \mathrm{mmol} / 1$ glucose. NA, not affected by glucose; low expression, mean signal intensity $<5 \quad(\log 2$ value). The sequence of letters and numbers shown to the left of each gene box corresponds to: (1) a letter indicating if maximal changes induced by glucose amount to more than fourfold (L, large), between four- and twofold (M, medium) or between 2- and 1.5-fold (S, small), and 2) the log-transformed mean signal intensity at $5.5 \mathrm{mmol} / \mathrm{l}$ glucose. *Validated by quantitative PCR (see ESM Table 4); " previously validated [16]. LDCV, large dense core vesicle (also known as secretory granule); RGS, regulator of G protein signalling; TRP, transient receptor potential cation channels; VDCC, voltage-dependant calcium channels 
at G20 is linked to cAMP generation rather than its metabolism.

As shown in Fig. 1b, GLP-1 raised cytosolic calcium $\left[\mathrm{Ca}^{2+}\right]_{\mathrm{i}}$ when added to cells kept for $72 \mathrm{~h}$ at $5.5 \mathrm{mmol} /$ 1 glucose (G5.5). This effect was reduced in cells cultured at G11 and completely lost in cells cultured at G20. To allow clear observation of the potentiating effects of GLP-1 and separate them from glucose effects, cells were kept at G15 for $30 \mathrm{~min}$ before the addition of GLP-1, which ensured a stable baseline. Note that preculture at G20 almost completely abolishes acute stimulation by glucose, as published previously [16]. Similarly to the effect of GLP1 alone, the response to GLP-1/glucose was pronounced in cells cultured in G5.5 but was largely decreased in cells cultured in G11 and abolished by preculture at G20. Increasing cAMP levels by forskolin raised $\left[\mathrm{Ca}^{2+}\right]_{\mathrm{i}}$ as expected [22]. The effect was reduced in cells cultured in
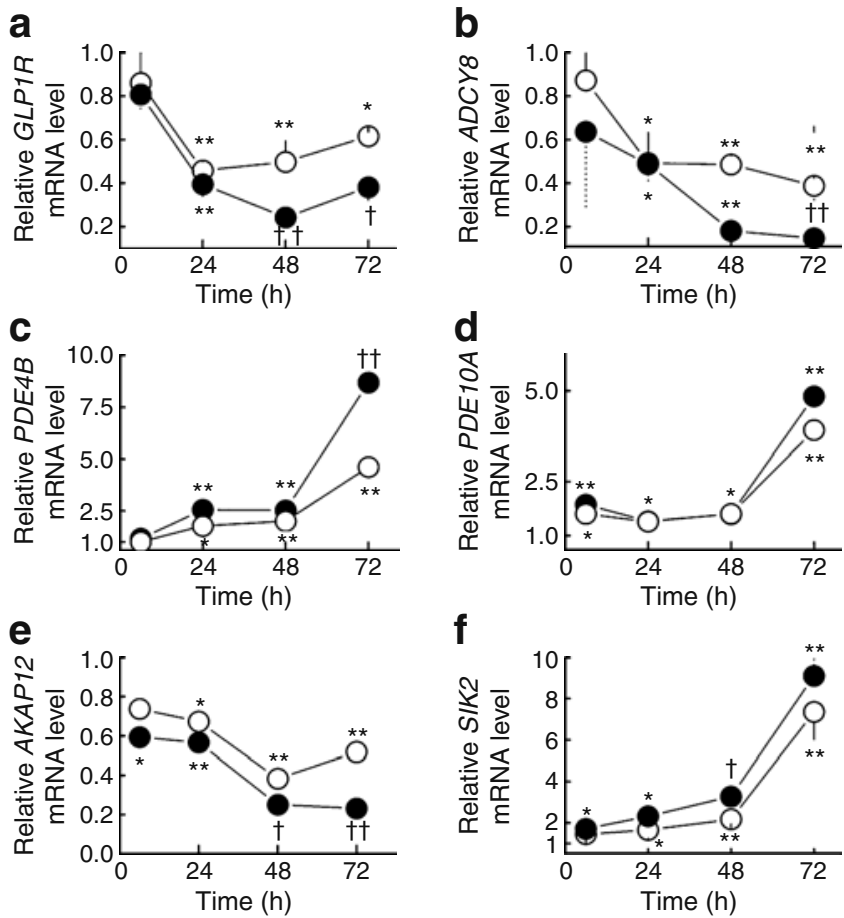

g
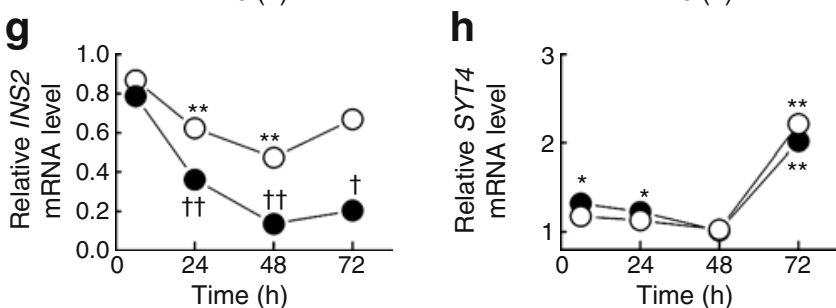

Fig. 3 Timecourse and protein levels of glucose-regulated expression of transcripts implicated in cAMP-mediated signalling and in exocytosis in INS-1E cells. a-h Quantitative PCR was performed on INS-1E cells cultured at $5.5,11$ or $20 \mathrm{mmol} / 1$ glucose for the indicated time range. Normalised expression values are given in terms of fraction of mRNA at G5.5 compared with G11 (white circles) or G20 (black circles); $n=3$, ANOVA (Bonferroni post hoc test): ${ }^{*} p<0.05$ and
G20, but to a lesser extent than observed for GLP-1. As decreased efficiency of GLP-1 or forskolin might be due to enhanced cAMP metabolism, the latter was blocked with IBMX. In the presence of $100 \mu \mathrm{mol} / 1 \mathrm{IBMX}$, the loss in forskolin-induced responses was less prominent (G5.5 vs G20, $687 \pm 101$ vs $441 \pm 61 \mathrm{nmol} / 1, n=10$ for each, $2 p<0.05$, Student's $t$ test), whereas the response to GLP-1 was lost to the same extent as in the absence of IBMX in cells cultured at G11 or G20 (data not shown).

We subsequently evaluated insulin secretion, an event downstream from changes in $\left[\mathrm{Ca}^{2+}\right]_{\mathrm{i}}$ or in cAMP $[12,13]$. Similar to calcium handling, the amplifying action of GLP1 was already lost in cells cultured at G11, whereas the effect of forskolin was reduced but still present after culture in G20 (Fig. 1c). As reported previously [16, 23], prolonged exposure to glucose leads to a reduction in insulin content (Fig. 1d). Although this certainly contributes

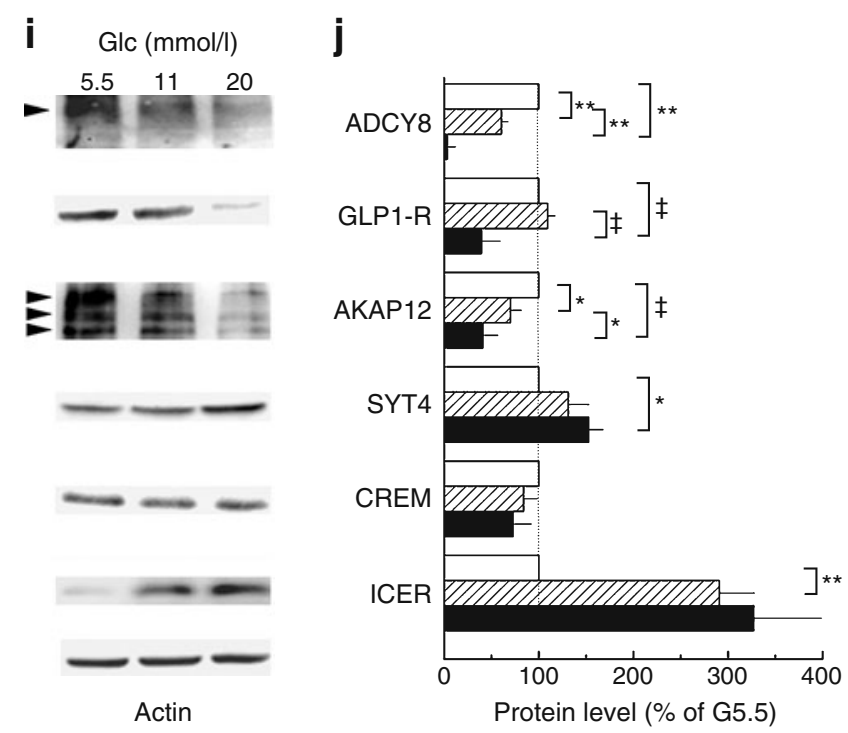

$*^{*} p<0.01$ compared with G5.5; ${ }^{\dagger} p<0.05$ and ${ }^{\dagger \dagger} p<0.01$ compared with G5.5 and to G11. i, j Cells were cultured for $72 \mathrm{~h}$ at G5.5 (white bars), G11 (hatched bars) or G20 (black bars) and the levels of specific proteins determined by immunoblotting of homogenates (i). Intensities were quantified, normalised against the level of actin and expressed as percentage of protein abundance in cells cultured at G5.5 (j). $n=3-5$, ${ }^{*} p<0.05 ;{ }^{* *} p<0.01 ;{ }^{\ddagger} p<0.02$ 
to the decrease in effects, it was not solely due to a reduction in vesicular hormone content by culture in G20, as similar effects were observed in cells transiently expressing human growth hormone as a secretory product under the control of a cytomegalovirus promoter (data not shown).

Prolonged exposure to elevated glucose remodels gene expression in G protein coupled receptor-and cAMP-linked pathways To get insight into underlying mechanisms, we examined the effect of glucose on gene expression by microarray analysis of INS-1E beta cells after $72 \mathrm{~h}$ culture at G5.5, G11 and G20 (see ESM Table 2). Interestingly, statistical evaluation of alterations in canonical pathways revealed the highest scores for two signalling pathways, via cAMP or more generally via $G$ protein coupled receptors (GPCRs), and two metabolic pathways, pyruvate metabolism and glycolysis/gluconeogenesis (see ESM Table 3).

To visualise changes in GPCR- and cAMP-mediated pathways, a map was constructed (Fig. 2), with colour assignment according to clusters (see ESM Fig. 1). In addition, quantitative PCR for a number of transcripts confirmed alterations measured by microarrays (see ESM Table 4). Several GPCRs are differentially regulated, including those known for their specific function in islets [24] such as the GLP1R, as well as G protein subunits and regulators of $G$ protein signalling. Among the adenylyl cyclases detected, calcium-sensitive Adcy 8 was strongly downregulated, whereas the major adenylyl cyclase, $A d c y 6$, remained unchanged, as did the more recently described soluble adenylyl cyclase, Adcy10. Indeed, Adcy 8 was the most downregulated transcript within the GPCR- or cAMPlinked pathways and ranked also among the five most downregulated identified transcripts in the total study. Concomitantly several phosphodiesterases were upregulated, including calcium-sensitive phosphodiesterase 1C $($ Pdelc). Changes in expression of other genes intervening in adenylyl cyclase organisation were noted, such as those coded for by the two A-kinase anchoring proteins, Akap7 and -12 , whereas expression remained constant for the immediate targets of cAMP Rapgef $3 / 4$ (also known as Epac1/2) or subunits of protein kinase A. Downstream of PKA we observed an increase for Sik2, a kinase inhibiting PKA-induced nuclear translocation of the transcription coactivator Torc, a major upregulation of CREM and a decrease in the transactivator Cited2. In addition to changes in cAMP-mediated signalling, altered expression of transcripts implicated in $\mathrm{Ca}^{2+}$ handling as well as $\mathrm{Ca}^{2+}$ targets was evident, including channels (Trpc4, Trpv1), pumps (Serca3 [also known as Atp2a3]) and links to the MAPkinase pathway (Rasgrp1 and -2,Dusp).

We performed time-course experiments to determine the sequence of events (Fig. 3a-h). Whereas Glp1r, Adcy8 and
Akap 12 were modulated by glucose at early time points and peaked at $48 \mathrm{~h}$, differences in PDEs reached their maximum later. Altered levels of GLP1R, ADCY8, AKAP12 and the vesicle protein synaptotagmin 4 (SYT4) were also evident at the protein level (Fig. 3i, j). Whereas Adcy 8 was already reduced by $40 \%$ at G11, Glp1r was significantly reduced only at G20. In addition, the transcriptional regulator of CRE, Crem, was not altered, whereas its splice variant Icer increased mainly between G5 and G11 with little if any further changes at G20.

We further assayed several key transcripts identified in our screen in rat (Fig. 4a, b) or human donor islets (Fig. 4c). Among the GPCRs stimulating adenylyl cyclase, Glplr was decreased but only after $24 \mathrm{~h}$. Again, Adcy 8 but not Adcy6 was strongly downregulated, and the production of Akap 12 decreased. The mRNA levels of the phosphodiesterases
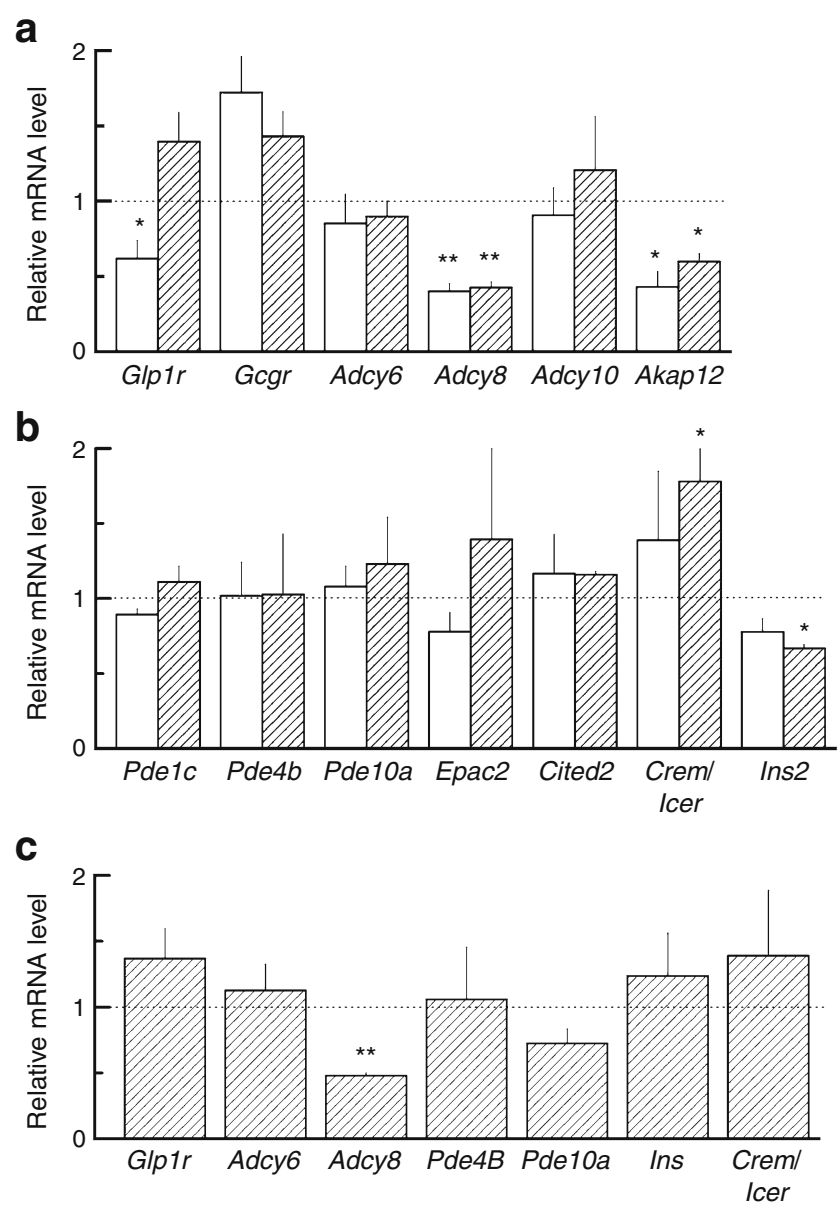

Fig. 4 Glucose regulates expression of transcripts of proteins implicated in cAMP-mediated signalling in rat islets and in human donor islets. Quantitative PCR was performed on samples from rat islets (a, b) or human donor islets (c) cultured at 10 or $30 \mathrm{mmol} /$ 1 glucose (rat islets) or 11 and $20 \mathrm{mmol} / 1$ glucose (human donor islets) for $24 \mathrm{~h}$ (white bars) or $72 \mathrm{~h}$ (hatched bars). Normalised expression values are depicted in terms of fraction of mRNA; $n=3-4 ; * p<0.05$; $* * p<0.01$ 
Pdelc and $-10 a$ did not increase above G10, as already observed in INS-1E cells (see Fig. 2). Similarly to clonal beta cells, levels of Crem/Icer were only slightly augmented between G10 and G30. In human donor islets (Fig. 4c) $A D C Y 8$ also declined by $60 \%$, whereas $A D C Y 6$ and $P D E$ s remained stable. Expression profiles for $C R E M / I C E R$ were similar to rat islets, although changes did not reach significance.

Re-expression of ADCY8 restores calcium signalling in clonal and primary cells The functional consequences of prolonged exposure to elevated glucose observed in INS-1E cells in conjunction with transcript profiling in cells and islets pointed towards a major role of ADCY8. To test whether downregulation of this minor isoform in beta cells indeed does play a role, we examined the outcome of its reexpression and of its knockdown on $\mathrm{Ca}^{2+}$ signalling. Transient transfection with a plasmid encoding ADCY8 led to re-expression of this enzyme in cells cultured at G20 and its location at the plasma membrane (Fig. 5a, b). As shown in Fig. 5d, e, culturing cells for 72 h at G20 instead of G5.5 abolished the potentiating effects of forskolin and GLP-1 on cells kept in G15 for 30 min before the addition of the drugs (see also Fig. 1a). Note that transient overabundance of ADCY8 in cells cultured at G5.5 did not increase the response to GLP-1 (Fig. 5e, right-hand side), indicating that ADCY8 is not rate limiting under these

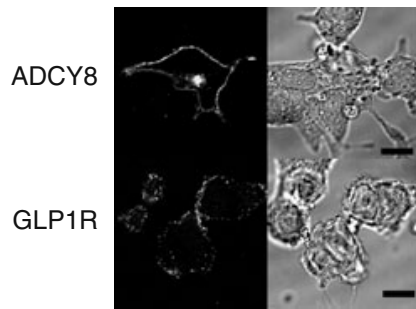

d

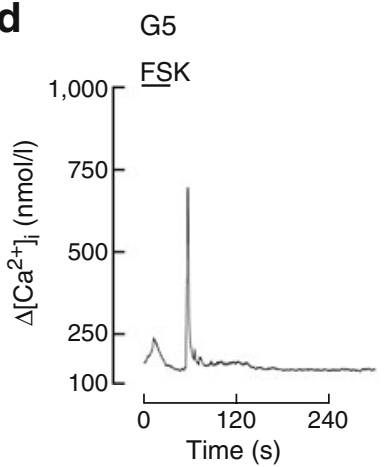

e

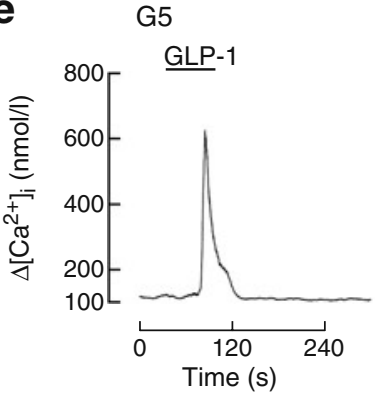

b

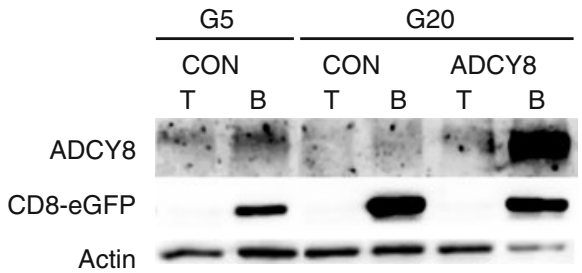

G20
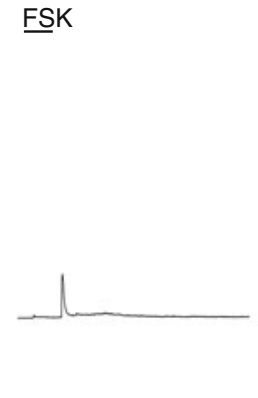

G20

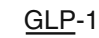

g

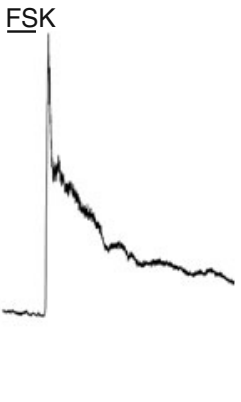

G20+ADCY8

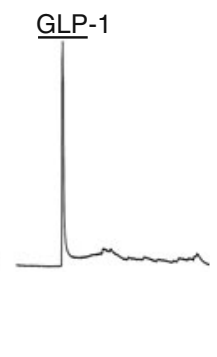

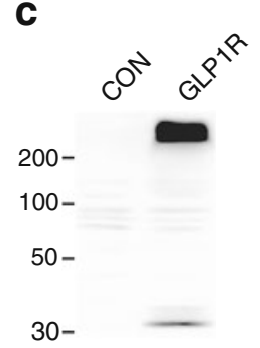
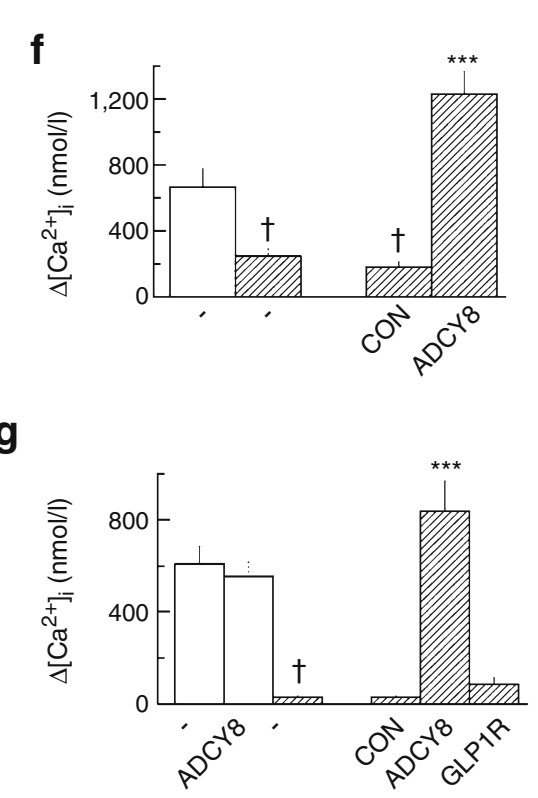

Fig. 5 Re-expression of adenylyl cyclase 8 restores GLP-1-regulated calcium handling in glucotoxicity in INS-1E cells. a Confocal images of INS-1E cells transiently expressing ADCY8-eGFP or myc-tagged GLP1R in (scale bar, $10 \mu \mathrm{m}$ ). b Immunoblots of sorted INS-1E cells transfected with plasmids encoding the extracellular and transmembrane domain of CD8 linked to eGFP and a control plasmid (pcDNA3, CON) or a plasmid encoding ADCY8. Cells were cultured for $72 \mathrm{~h}$ either at G5 or at G20, subsequently sorted using anti-CD8 beads ( $\mathrm{T}$, total; B, cells bound to beads) and subjected to immunoblots using antibodies against adenylyl cyclase 8 (ADCY8), eGFP (CD8eGFP) or actin as a control. c Immunoblot of homogenates of cells transfected with a control plasmid (CON, pcDNA3) or a plasmid coding for GFP-tagged GLP-1 receptor (GLP1R). Representative recordings of cells exposed to FSK $(1 \mu \mathrm{mol} / \mathrm{l})(\mathbf{d})$ or GLP-1 $(10 \mathrm{nmol} / \mathrm{l})(\mathbf{e})$. Cells had been cultured for $72 \mathrm{~h}$ at G5.5 or G20 and left untransfected (-) or transfected with either a control plasmid (CON, pcDNA3) or a plasmid coding for ADCY8. e, f Summary of results (-, nontransfected; CON, pcDNA3; GLP1R, GLP-1 receptor) of cells cultured for $72 \mathrm{~h}$ at G5 (white bars) or G20 (hatched bars); $n=16$ $40 ;{ }^{\dagger} p<0.001$ compared with culture at G5.5; $* * * p<0.001$ compared with $\mathrm{CON}$ or non-transfected cells cultured at G20 
conditions. In cells cultured at G20, the effects of forskolin and of GLP-1 were completely restored by re-expression of ADCY8. By contrast, overabundance of the GLP1R in cells cultured at G20 did not restore the effect of GLP-1 (Fig. 5e, right-hand side), although the receptor was clearly expressed and located at the plasma membrane (Fig. 5a, c). Most importantly, these effects were also observed in rat primary cells upon re-expression of ADCY8 (Fig. 6). GLP-1 induced a prominent increase in $\left[\mathrm{Ca}^{2+}\right]_{i}$ in cells precultured at $\mathrm{G} 11$, and preculture at G30 completely abolished hormone effects. Again, re-expression of ADCY8, but not of GLP1R, restored incretin-induced responses.

ADCY8 is required for normal calcium signalling To further evaluate the role of this minor isoform, we downregulated its expression by shRNA-mediated knockdown. Levels of transiently expressed ADCY8-eGFP or of endogenous ADCY8 were decreased by the expression of shRNAs and plasmid psh-4 was used in subsequent assays (Fig. 7a, b). GLP-1 induced a robust increase in $\left[\mathrm{Ca}^{2+}\right]_{\mathrm{i}}$ in control-transfected cells cultured at G5 and placed at G15 for $30 \mathrm{~min}$ before the addition of the hormone. Knockdown of endogenous $A d c y 8$ (shADCY8) reduced the response by $90 \%$. By contrast, knockdown of Adcy 8 diminished the effect of forskolin on $\left[\mathrm{Ca}^{2+}\right]_{i}$ only by one-third (Fig. $7 \mathrm{~d}$, e), suggesting that only part of total cellular adenylyl cyclase
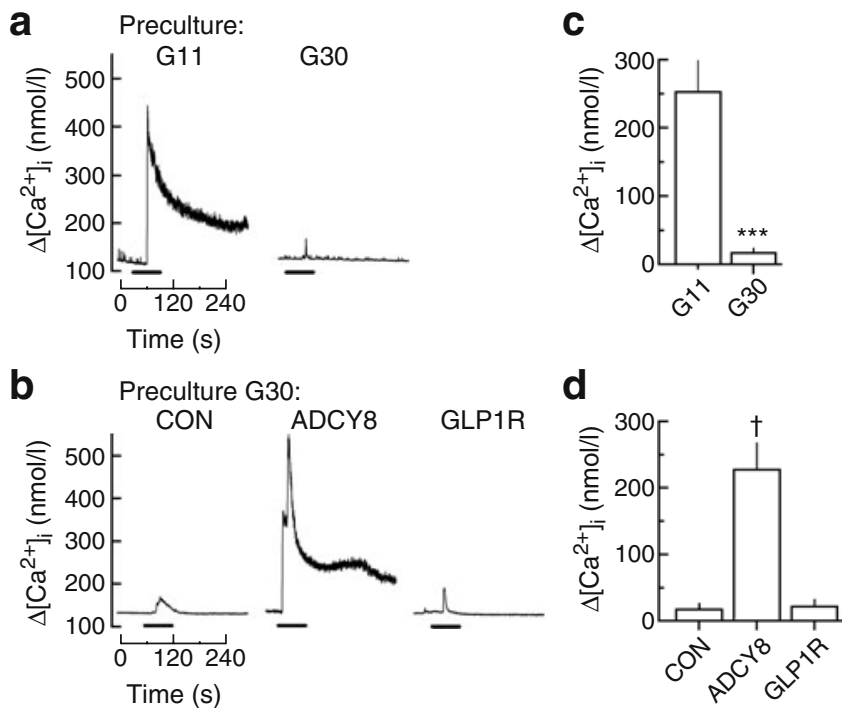

Fig. 6 Re-expression of ADCY8, but not of GLP1R, restores GLP-1 effects on cytosolic calcium in primary rat islet cells. (a, b) Representative calcium traces of dispersed rat islet cells. Additions of GLP-1 (10 nmol/l) are indicated by bars. (a) Effect of preculture $(72 \mathrm{~h})$ at 11 or $30 \mathrm{mmol} / \mathrm{l}$ glucose; (b) effect of transient expression of control plasmid (pcDNA3; CON), ADCY8 or GLP1R on $\left[\mathrm{Ca}^{2+}\right]_{\mathrm{i}}$ in dispersed rat islet-cells precultured for $72 \mathrm{~h}$ at G30. c, d Summary of results, $n=7-16$; $* * * p<0.001$ compared with preculture at G11; ${ }^{\dagger} p<$ 0.001 compared with control (CON) or GLP1R transfected cells activity is reduced. The effects of $\mathrm{KCl}$ and thapsigargin on $\left[\mathrm{Ca}^{2+}\right]_{\mathrm{i}}$ remained unchanged (Fig. 7e).

ADCY8 is required for GLP-1-induced cAMP generation and CRE activation Subsequently we asked whether cAMP generation and downstream effects, such as regulation of CRE, may be mediated by ADCY 8 and recovered by its reexpression. Knockdown of Adcy 8 as well as prolonged exposure to elevated glucose abolished GLP-1-induced cAMP accumulation, and re-expression of $A d c y 8$ recovered two-thirds of the GLP-1 net effect (Fig. 8a). Moreover, culture at G20 for $72 \mathrm{~h}$ reduced forskolin- and GLP-1induced activation of CRE (Fig. 8b). Re-expression of Adcy 8 induced full recovery of CRE activation by both agents in cells cultured at G20. The amplification of the effect of glucose by GLP-1 was lost upon knockdown of Adcy8 (Fig. 8c). However, knockdown of Adcy 8 did not alter glucose-induced regulation of CRE, which may thus occur independently from ADCY8.

ADCY8 is required for cAMP-induced potentiation of exocytosis Re-expression of Adcy8 did not recover stimulation of hormone secretion by glucose or by glucose and forskolin in cells cultured in G20 for $72 \mathrm{~h}$, regardless of whether early $(0-10 \mathrm{~min})$ or late phases $(10-45 \mathrm{~min})$ of release were measured (data not shown). The lack of reconstitution of exocytosis by re-expression of $A d c y 8$ is in line with previous reports that central components of the secretory machinery are downregulated under these conditions [16, 25-27]. To address specifically the role of ADCY8 in the regulation of exocytosis, the final step in secretion, we resorted to capacitance measurements by patch clamp (Fig. 9). Stimulating exocytosis via intracellular dialysis with $1.5 \mu \mathrm{mol} / 1$ free calcium allowed circumvention of early effects of glucose such as metabolism, membrane depolarisation and calcium influx. The ensuing increase in membrane capacitance was not changed by knockdown of Adcy8. Direct stimulation of exocytosis by dialysis with calcium was further enhanced by the addition of forskolin/IBMX (Fig. 5a) reflecting amplification [28]. Upon knockdown of Adcy8 a complete loss of the effect induced by forskolin/IBMX was observed, demonstrating a prominent role of this isoform in the amplification of exocytosis by cAMP. Inspection of the kinetics of exocytosis revealed that the early phase (up to 15 s) remains unaltered, whereas subsequent exocytosis is largely reduced by the knockdown of $A d c y 8$, indicating its involvement mainly in the second phase.

\section{Discussion}

Chronically elevated glucose alters glucose detection, its metabolism and subsequent calcium handling [3] as well as 


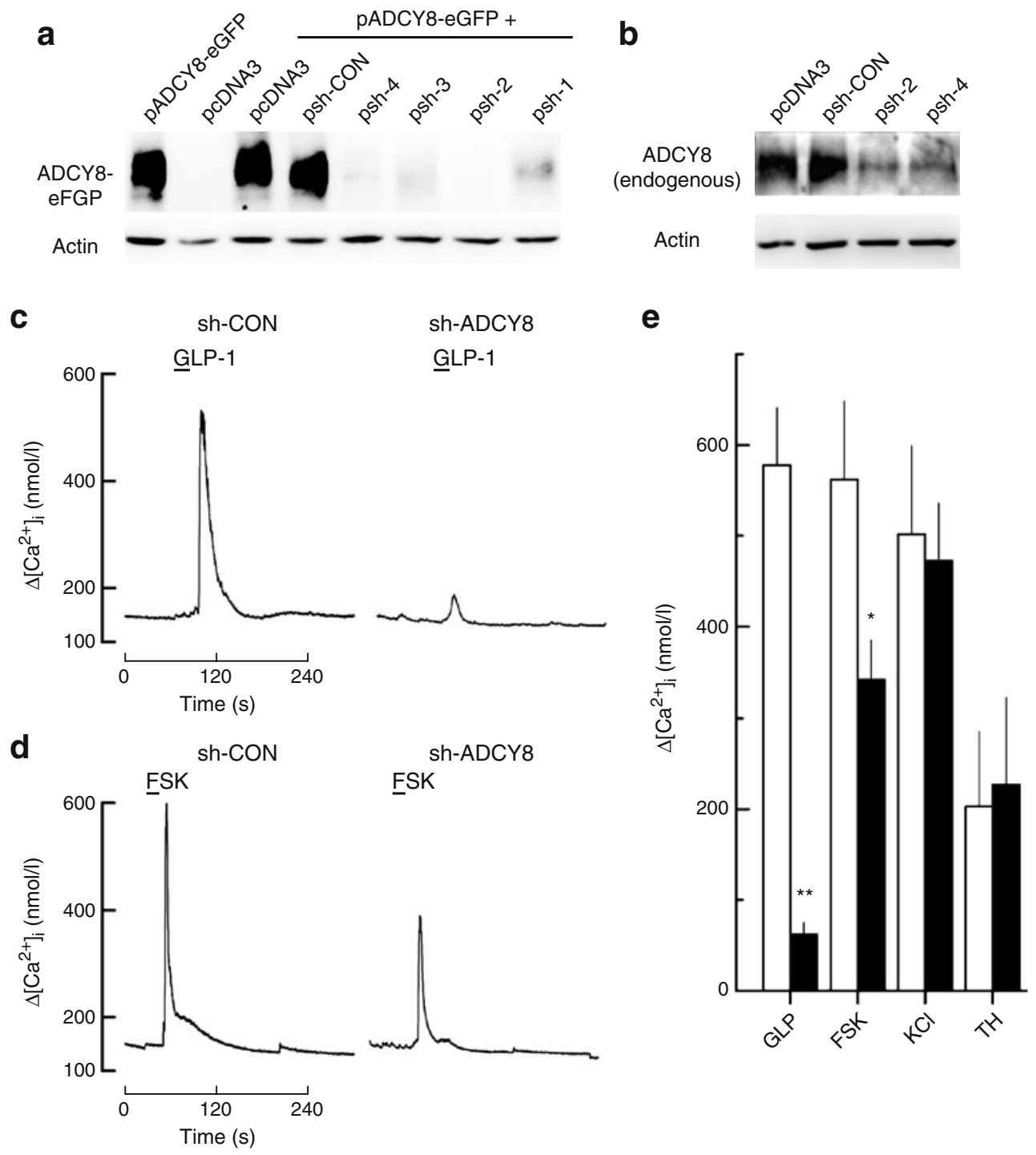

Fig. 7 Adenylyl cyclase 8 is required for rises in cytosolic calcium induced by GLP-1. a Knockdown of transiently expressed ADCY8eGFP. Immunoblots of INS-1E cells transfected with plasmids coding for eGFP-tagged ADCY8 (pADCYeGFP) or the control plasmid pcDNA3 (pcDNA) or co-transfected with pADCYeGFP and either pcDNA3, a scrambled shRNA sequence (psh-NC) or plasmids encoding different shRNAs directed against ADCY8 (psh-1 to 4). Immunoblots were incubated with antibodies against eGFP (ADCY8) or against actin. b Knockdown of endogenous ADCY8. Cells were transfected with plasmids coding either for ADCY8 (pADCY8), control plasmids (pcDNA3, psh-CON) or with plasmids encoding an

cellular insulin content $[16,23]$. By contrast, it has only a minor effect on apoptosis under the conditions used $[16,19]$. Our data now demonstrate a profound remodelling of signalling pathways linked to GPCRs such as the GLP-1 receptor, to cAMP and calcium. Moreover, a specific isoform of adenylyl cyclase, ADCY8, ranked among the most downregulated transcripts in this study as well as in a previous one in rat islets [19]. ADCY8 has previously been proposed as glucose/GLP-1 coincidence detector according
shRNA directed against ADCY8 (psh-2 and 4). Immunoblots were stained with antibodies against ADCY8 or against actin. c, d Representative recordings of cells cultured for $72 \mathrm{~h}$ at G5.5 and transfected either with psh-NC (sh CON) or psh-4 (sh-ADCY8). Cells were stimulated with either G15 $(n=30-51)$, with GLP-1 in the presence of G15 (10 nmol/1, $n=26-31)$ or with forskolin (FSK, $1 \mu \mathrm{mol} / 1 ; n=21-24)$. e Summary of results $(25 \mathrm{mmol} / 1 \mathrm{KCl}, n=10$; TH, $200 \mathrm{nmol} / 1$ thapsigargin, $n=4-5$; sh-Con, white bars; sh-ADCY , black bars); ${ }^{*} p<0.05$ and ${ }^{* *} p<0.01$ compared with control transfected cells (sh-CON)

to its biochemical characteristics and cell-specific production [29]. Our functional assays revealed that this isoform is crucial for incretin signalling in beta cells, and its reduced production constitutes an important element in glucotoxicity.

Changes in intracellular levels of cAMP rely on intricate dynamics between adenylyl cyclases and phosphodiesterases [30]. Several arguments indicate that effects of prolonged exposure to elevated levels of glucose are linked rather to changes in $\mathrm{ADCY} 8$ than in phosphodiesterases 
Fig. 8 Re-expression of ADCY8 recovers GLP-1 induced generation of cAMP and activation of CRE in INS1-E cells cultured at $20 \mathrm{mmol} / 1$ glucose. a INS-1E cells were co-transfected with pCD8eGFP and either a control plasmid (CON shRNA, white bars), a plasmid encoding an shRNA directed against ADCY8 (sh ADCY8, psh-4; hatched bars) or a plasmid expressing adenylyl cyclase 8 (pADCY8, black bars). Cells were cultured for $72 \mathrm{~h}$ either at G5.5 or at G20, subsequently sorted using anti-CD8 beads and cAMP production (in the presence of $10 \mu \mathrm{mol} / 1 \mathrm{IBMX}, 5.5 \mathrm{mmol} / 1$ glucose) was measured in the absence or presence of GLP-1 (10 nmol/1); $n=6,{ }^{*} p$ $<0.01$ vs absence of GLP- $1 ; * p<0.01$ vs shRNA CON. b INS-1E cells were cultured for $72 \mathrm{~h}$ at G5 or G20 (hatched or black bars) and cotransfected with pCRE-luc and either a control plasmid (pCON, pcDNA3; white bars) or a plasmid expressing adenylyl cyclase 8 (pADCY8; black bars). Cells were subsequently kept for $30 \mathrm{~min}$ at $2.8 \mathrm{mmol} / 1$ glucose alone $(\mathrm{G} 2.8)$ or at $2.8 \mathrm{mmol} / 1$ glucose in the presence of forskolin (FSK, $1 \mu \mathrm{mol} / \mathrm{l})$ or of GLP-1 (10 nmol/l), washed and $6 \mathrm{~h}$ later activation of CRE was determined. Data are expressed as percentage of activity compared with culture at G5.5/pCON; $n=4,{ }^{*} p<$ 0.05 vs absence of FSK or GLP-1 (G2.8); $* * p<0.01$ compared with cells cultured at G5.5; ${ }^{\dagger} p<0.01$ vs pCON at G20. c INS-1E cells were cultured at G5.5 and co-transfected with pCRE-Luc and either a control plasmid (sh CON, psh-NC, white bars) or a plasmid coding for shRNA directed against ADCY8 (sh ADCY8, psh-4, hatched bars). Cells were either kept at $2.8 \mathrm{mmol} / \mathrm{l}$ glucose $(\mathrm{G} 2.8)$ or stimulated for $1 \mathrm{~h}$ with $15 \mathrm{mmol} / \mathrm{l}$ glucose in the absence or presence of $10 \mathrm{nmol} / 1 \mathrm{GLP}-1$ (G15; G15+GLP-1), washed and processed as in A. Data are expressed as percentage of activity compared with culture at G5.5/psh CON; $n=6$; ${ }^{*} p<0.05$ vs G2.8; ${ }^{\dagger} 2 p<0.05$ vs absence of GLP- $1 ;{ }^{\star} 2 p<0.05$ compared with control transfected cells (sh CON) exposed to G15/GLP-1

(PDEs). Decreased cAMP levels as well as a loss in calcium responses were still observed in the presence of the PDE inhibitor IBMX and changes in production occurred at a later time point in PDEs as compared with ADCY8. Furthermore, only a subset of PDEs interferes with secretion: mainly PDE3B, but also PDE1C, PDE4C, PDE5A and PDE8B [31]. Among these, prolonged exposure to glucose upregulated only Pdelc, mainly at low and intermediate glucose levels, whereas $P d e 3 b$ was downregulated. As the latter event enhances GLP-1 induced insulin secretion [32], it does not account for loss of incretin effects.

Our data confirm the absolute requirement of ADCY8 for GLP-1 effects on cAMP and $\left[\mathrm{Ca}^{2+}\right]_{\mathrm{i}}$ although it constitutes only a quantitatively minor isoform as compared with ADCY6 in INS-1E cells and rat or human islets [29, 33]. Its functional preponderance over ADCY6 is not too surprising as the latter is inhibited by calcium, similar to ADCY5 [34]. A second calcium-stimulated adenylyl cyclase is produced in beta cells, ADCY1. In contrast to ADCY1, ADCY8 responds more rapidly to changes in calcium and gives rise to oscillations in cAMP in response to $\mathrm{Ca}^{2+}$-transients [35] and may be better suited to the physiology of beta cells. Expression of the direct downstream effectors of cAMP, PKA as well as EPAC, remained stable further pointing towards ADCY8 as an important player. Most importantly, our re-expression experiments
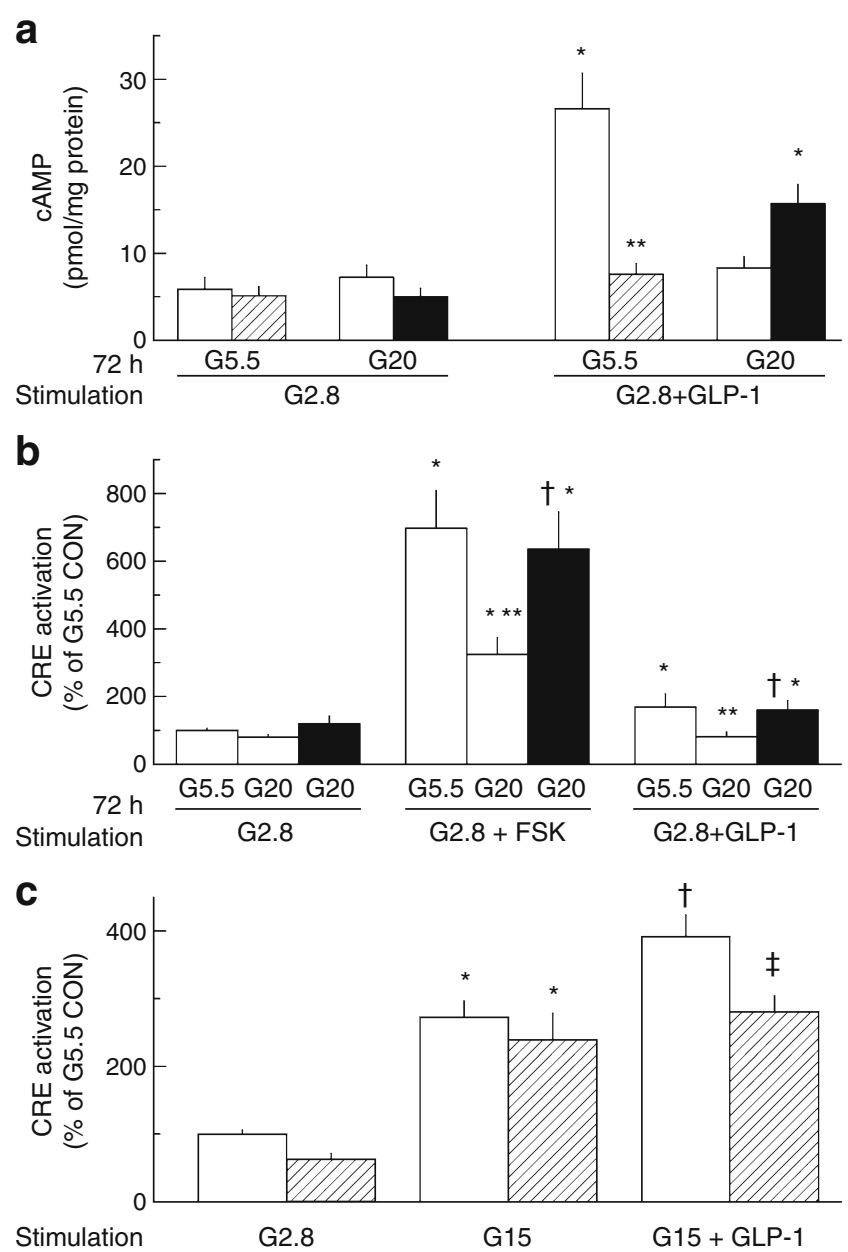

demonstrate that calcium, cAMP and CRE responses to GLP-1 can be recovered by restoring levels of ADCY8. Within the same line of arguments, knockdown of Adcy8 imitated the loss or decrease in forskolin or GLP-1 response in $\left[\mathrm{Ca}^{2+}\right]_{\mathrm{i}}$ and cAMP observed in glucotoxicity. This provides the molecular identity for previous observations on calcium-dependency of GLP-1 effects [29] and places this isoform in a central position. Additional, though indirect, arguments for a role of ADCY8 in glucose homeostasis are provided by genetic data. A quantitative trait locus was identified containing the ADCY8 gene with significant linkage to fasting hyperglycaemia and impaired glucose tolerance in the Akita mouse, a non-obese model for type 2 diabetes [36]. A linkage between ADCY8 and type 2 diabetes has recently been mentioned in a genetic study in humans [37].

Prolonged exposure to elevated glucose remodels the production of numerous GPCRs required to adapt beta cells to physiological demands [24]. The GLP-1 receptor was downregulated in INS-1E cells, whereas significant changes were apparent in rat islets after 24 , but not after $72 \mathrm{~h}$. These results differ from observations in pancreatectomised rats, 
a

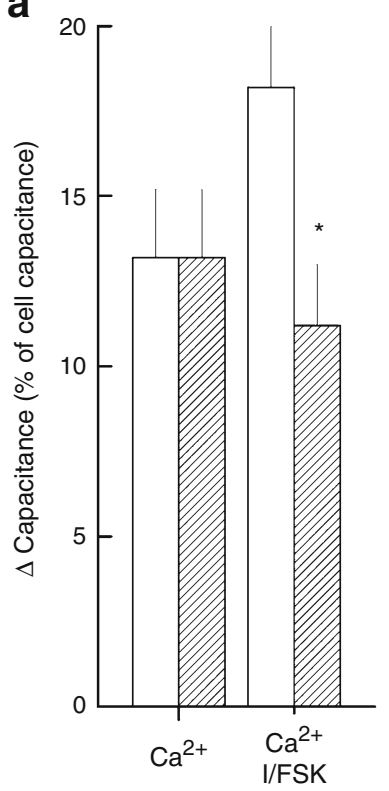

b

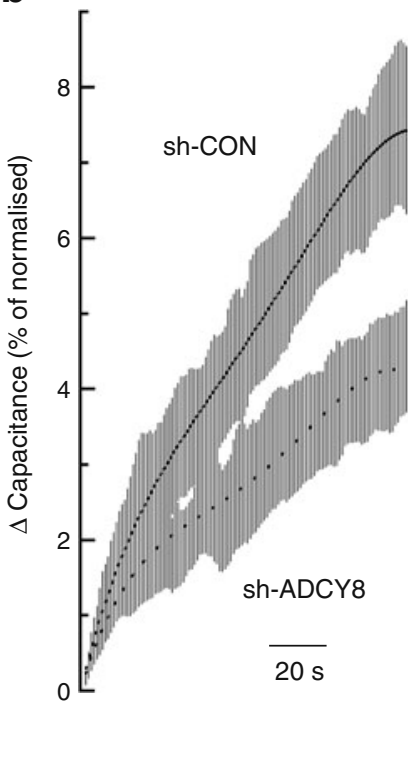

Fig. 9 ADCY8 is required for amplification of exocytosis by adenylyl cyclases. a Summary of changes in capacitance during exocytosis elicited by intracellular dialysis of $1.5 \mu \mathrm{mol} / 1$ free calcium in standard buffer $\left(\mathrm{Ca}^{2+}\right)$ in the absence or presence of $1 \mu \mathrm{mol} / 1 \mathrm{FSK} / 100 \mu \mathrm{mol} /$ 1 IBMX $\left(\mathrm{Ca}^{2+} \mathrm{I} / \mathrm{FSK}\right)$ in the bath. White bars, sh CON; hatched bars, sh-ADCY8. Values were normalised to basal cell membrane capacitance and expressed as percentage of change; $n=19-31 ; * 2 p<0.05$ (Student's $t$ test). b Timecourse of capacitance recordings of INS-1E cells transfected with psh-NC (CON) or psh-4 (ADCY8). Given are the SEMs of all recordings $(n=14-15)$ and the fitted curves (dashed lines). Exocytosis was elicited by dialysis with $1.5 \mu \mathrm{mol} / 1$ free calcium through the patch pipette in the absence or presence of $1 \mu \mathrm{mol} / \mathrm{FSK} /$ $100 \mu \mathrm{mol} / 1 \mathrm{IBMX}$ in the bath. Recordings started at $t=0$ when wholecell configuration was established

$d b / d b$ mice or islets cultured at elevated glucose [38]. We have no ready explanation for this difference except that islets used in our study were precultured for up to a week to recover from the stress of the isolation procedure. Note that data similar to ours on $24 \mathrm{~h}$ effects of glucose have been published by others [39]. As re-expression of ADCY8, but not of the glucagon-like peptide 1 receptor (GLP1R), restored calcium signalling in clonal and primary cells, post-receptor events may represent the most vulnerable part of the pathway.

Regulation of gene expression via the calcium- and cAMP-responsive element CRE is important for beta cell function and survival. Glucose and GLP-1 can activate CRE via PKA either directly or through mitogen-activated kinases (ERK) [40, 41]. Both pathways are probably compromised at G11 by increased expression of the phosphatase DUSP14 acting on ERK [42] and the kinase SIK2 impeding nuclear translocation of CRTC2 (also known as TORC2), a CREB coactivator [43]. Our data also confirm that glucose leads to a large increase in the inducible repressor isoform of CREM, ICER, which inhibits CRE

activation $[25,44]$. Changes were present between G5.5 and G11 with little further alteration at G20 in clonal cells and islets. Interestingly, loss of forskolin- or GLP-1induced CRE activation was reverted upon re-expression of ADCY8. Thus, CREM/ICER as well as DUSP and SIK are important physiological regulators, but their alterations seem to be less disruptive than those of ADCY8.

Compartmentalisation and isoform specificity confer selectivity in cAMP signalling [34]. Specific scaffold proteins, the AKAPs, ensure defined localisation of enzymes implicated in cAMP generation [45] and their differential expression by glucose could further disturb signalling. Isoform specificity for effectors was evident as only GLP-1 induced increases in $\left[\mathrm{Ca}^{2+}\right]_{\mathrm{i}}$ and potentiation of CRE activation, but not glucose-induced activation of CRE relied on ADCY8. Recently ADCY10, a forskolininsensitive isoform, has been identified as mediator of glucose-induced phosphorylation of ERK [46]. Its presence may explain the persistence of glucose-induced CRE activation after ADCY8 knockdown. ADCY10 is probably not involved in glucotoxicity as glucose did not affect its expression in INS-1E cells or rat islets.

The specificity of adenylyl cyclase isoforms was further underlined by measuring exocytosis, the final step in insulin secretion. Insulin exocytosis is triggered by calcium and amplified by cAMP-raising agents, thus providing an adequate response to physiological demands [13]. Although ADCY 8 constitutes only a minor adenylyl cyclases [29, 33], its expression was required for cAMP-induced amplification of exocytosis. The observed defect may reside in vesicle priming, reminiscent of the specific role of ADCY 8 in hippocampal synapses despite the presence of calciumsensitive ADCY1 [47].

Collectively our data highlight the role of signalling pathways in glucose desensitisation/glucotoxicity and specifically identify the role of the calcium-sensitive adenylyl cyclase 8 in this setting and in normal signalling. The potential importance of altered signalling pathways, including those linked to GPCRs or to adenylate cyclases, in the pathogenesis of type 2 diabetes has also been underscored by recent genetic studies [48-50].

Acknowledgements This work was supported by grants from the University of Bordeaux I (B. Roger, J. Lang), the MENRT and ALFEDIAM/Société française de Diabétologie (M. Dubois, M. Raoux and J. Lang). N. Moustaïd-Moussa was a recipient of a Fulbright Aquitaine Scholarship. J.-C. Jonas is a Senior Research Associate of the Fonds de la Recherche Scientifique-FNRS, Belgium. Human islet production was supported by the Juvenile Diabetes Research Foundation (ECIT, to F. Pattou). We thank G. Drutel and T. Leste-Lasserre (INSERM U, Université de Bordeaux 2) for initial help with quantitative PCRs and M. Bennassy, A. Milochau and C. Blatche for perfect technical assistance.

Duality of interest The authors declare that there is no duality of interest associated with this manuscript. 


\section{References}

1. MacDonald PE, Rorsman P (2007) The ins and outs of secretion from pancreatic beta-cells: control of single-vesicle exo- and endocytosis. Physiology (Bethesda) 22:113-121

2. Unger RH, Grundy S (1985) Hyperglycaemia as an inducer as well as a consequence of impaired islet cell function and insulin resistance: implications for the management of diabetes. Diabetologia 28:119-121

3. Poitout V, Robertson RP (2008) Glucolipotoxicity: fuel excess and beta-cell dysfunction. Endocr Rev 29:351-366

4. Hojberg PV, Vilsboll T, Rabol R et al (2009) Four weeks of nearnormalisation of blood glucose improves the insulin response to glucagon-like peptide-1 and glucose-dependent insulinotropic polypeptide in patients with type 2 diabetes. Diabetologia 52:199-207

5. Knop FK, Vilsboll T, Hojberg PV et al (2007) Reduced incretin effect in type 2 diabetes: cause or consequence of the diabetic state? Diabetes 56:1951-1959

6. Holst JJ (2007) The physiology of glucagon-like peptide 1 . Physiol Rev 87:1409-1439

7. Buteau J, Foisy S, Joly E, Prentki M (2003) Glucagon-like peptide 1 induces pancreatic beta-cell proliferation via transactivation of the epidermal growth factor receptor. Diabetes 52:124-132

8. MacDonald PE, Wang X, Xia F et al (2003) Antagonism of rat betacell voltage-dependent $\mathrm{K}^{+}$currents by exendin 4 requires dual activation of the $\mathrm{cAMP} /$ protein kinase $\mathrm{A}$ and phosphatidylinositol 3-kinase signaling pathways. J Biol Chem 278:52446-52453

9. Holz GG, Kang G, Harbeck M, Roe MW, Chepurny OG (2006) Cell physiology of cAMP sensor Epac. J Physiol 577:5-15

10. Gromada J, Dissing S, Bokvist K et al (1995) Glucagon-like peptide I increases cytoplasmic calcium in insulin-secreting beta TC3-cells by enhancement of intracellular calcium mobilization. Diabetes 44:767-774

11. Tsuboi T, da Silva XG, Holz GG, Jouaville LS, Thomas AP, Rutter GA (2003) Glucagon-like peptide-1 mobilizes intracellular $\mathrm{Ca}^{2+}$ and stimulates mitochondrial ATP synthesis in pancreatic MIN6 beta-cells. Biochem J 369:287-299

12. Lang J (1999) Molecular mechanisms and regulation of insulin exocytosis as a paradigm of endocrine secretion. Eur J Biochem 259:3-17

13. Henquin JC (2009) Regulation of insulin secretion: a matter of phase control and amplitude modulation. Diabetologia 52:739-751

14. Kim SJ, Nian C, Widenmaier S, McIntosh CH (2008) Glucosedependent insulinotropic polypeptide-mediated up-regulation of beta-cell antiapoptotic Bcl-2 gene expression is coordinated by cyclic AMP (cAMP) response element binding protein (CREB) and cAMP-responsive CREB coactivator 2. Mol Cell Biol 28:1644-1656

15. Khaldi MZ, Guiot Y, Gilon P, Henquin JC, Jonas JC (2004) Increased glucose sensitivity of both triggering and amplifying pathways of insulin secretion in rat islets cultured for $1 \mathrm{wk}$ in high glucose. Am J Physiol Endocrinol Metab 287:E207-E217

16. Dubois M, Vacher P, Roger B et al (2007) Glucotoxicity inhibits late steps of insulin exocytosis. Endocrinology 148:1605-1614

17. Lajus S, Vacher P, Huber D et al (2006) Alpha-latrotoxin induces exocytosis by inhibition of voltage-dependent $\mathrm{K}^{+}$channels and by stimulation of L-type $\mathrm{Ca}^{2+}$ channels via latrophilin in beta-cells. J Biol Chem 281:5522-5531

18. Dubois M, Kerr-Conte J, Gmyr V et al (2004) Non-esterified fatty acids are deleterious for human pancreatic islet function at physiological glucose concentration. Diabetologia 47:463-469

19. Bensellam M, van Lommel L, Overbergh L, Schuit FC, Jonas JC (2009) Cluster analysis of rat pancreatic islet gene mRNA levels after culture in low-, intermediate- and high-glucose concentrations. Diabetologia 52:463-476
20. Patton C, Thompson S, Epel D (2004) Some precautions in using chelators to buffer metals in biological solutions. Cell Calcium $35: 427-431$

21. Dyachok O, Idevall-Hagren O, Sagetorp J et al (2008) Glucoseinduced cyclic AMP oscillations regulate pulsatile insulin secretion. Cell Metab 8:26-37

22. Siegel EG, Wollheim CB, Kikuchi M, Renold AE, Sharp GW (1980) Dependency of cyclic AMP-induced insulin release on intra- and extracellular calcium in rat islets of Langerhans. J Clin Invest 65:233-241

23. Roche E, Assimacopoulos-Jeannet F, Witters LA et al (1997) Induction by glucose of genes coding for glycolytic enzymes in a pancreatic beta-cell line (INS-1). J Biol Chem 272:3091-3098

24. Regard JB, Kataoka H, Cano DA et al (2007) Probing cell typespecific functions of Gi in vivo identifies GPCR regulators of insulin secretion. J Clin Invest 117:4034-4043

25. Abderrahmani A, Cheviet S, Ferdaoussi M, Coppola T, Waeber G, Regazzi R (2006) ICER induced by hyperglycemia represses the expression of genes essential for insulin exocytosis. EMBO J 25:977-986

26. Tsuboi T, Ravier MA, Parton LE, Rutter GA (2006) Sustained exposure to high glucose concentrations modifies glucose signaling and the mechanics of secretory vesicle fusion in primary rat pancreatic beta-cells. Diabetes 55:1057-1065

27. Olofsson CS, Collins S, Bengtsson M et al (2007) Long-term exposure to glucose and lipids inhibits glucose-induced insulin secretion downstream of granule fusion with plasma membrane. Diabetes 56:1888-1897

28. Renstrom E, Eliasson L, Rorsman P (1997) Protein kinase Adependent and -independent stimulation of exocytosis by cAMP in mouse pancreatic B cells. J Physiol 502(Pt 1):105-118

29. Delmeire D, Flamez D, Hinke SA, Cali JJ, Pipeleers D, Schuit F (2003) Type VIII adenylyl cyclase in rat beta cells: coincidence signal detector/generator for glucose and GLP-1. Diabetologia 46:1383-1393

30. Fridlyand LE, Harbeck MC, Roe MW, Philipson LH (2007) Regulation of cAMP dynamics by $\mathrm{Ca}^{2+}$ and $\mathrm{G}$ protein-coupled receptors in the pancreatic beta-cell: a computational approach. Am J Physiol Cell Physiol 293:C1924-C1933

31. Waddleton D, Wu W, Feng Y et al (2008) Phosphodiesterase 3 and 4 comprise the major cAMP metabolizing enzymes responsible for insulin secretion in INS-1 (832/13) cells and rat islets. Biochem Pharmacol 76:884-893

32. Choi YH, Park S, Hockman S et al (2006) Alterations in regulation of energy homeostasis in cyclic nucleotide phosphodiesterase 3B-null mice. J Clin Invest 116:3240-3251

33. Kutlu B, Burdick D, Baxter D et al (2009) Detailed transcriptome atlas of the pancreatic b-cell. BMC Med Genomics 2:3

34. Willoughby D, Cooper DM (2007) Organization and $\mathrm{Ca}^{2+}$ regulation of adenylyl cyclases in cAMP microdomains. Physiol Rev 87:965-1010

35. Masada N, Ciruela A, MacDougall DA, Cooper DMF (2009) Distinct mechanisms of regulation by $\mathrm{Ca}^{2+} /$ calmodulin of type 1 and 8 adenylyl cyclases support their different physiological roles. J Biol Chem 284:4451-4463

36. Takeshita S, Moritani M, Kunika K, Inoue H, Itakura M (2006) Diabetic modifier QTLs identified in F2 intercrosses between Akita and A/J mice. Mamm Genome 17:927-940

37. de Mooij-van Malsen AJ, van Lith HA, Oppelaar H et al (2009) Interspecies trait genetics reveals association of Adcy8 with mouse avoidance behavior and a human mood disorder. Biol Psychiatry 66:1123-1130

38. Xu G, Kaneto H, Laybutt DR et al (2007) Downregulation of GLP-1 and GIP receptor expression by hyperglycemia: possible contribution to impaired incretin effects in diabetes. Diabetes 56:1551-1558 
39. Zhou J, Livak MF, Bernier M et al (2007) Ubiquitination is involved in glucose-mediated downregulation of GIP receptors in islets. Am J Physiol Endocrinol Metab 293:E538-E547

40. Briaud I, Lingohr MK, Dickson LM, Wrede CE, Rhodes CJ (2003) Differential activation mechanisms of Erk-1/2 and p70 (S6K) by glucose in pancreatic beta-cells. Diabetes 52:974983

41. Costes S, Broca C, Bertrand G et al (2006) ERK1/2 control phosphorylation and protein level of cAMP-responsive elementbinding protein: a key role in glucose-mediated pancreatic betacell survival. Diabetes 55:2220-2230

42. Klinger S, Poussin C, Debril MB, Dolci W, Halban PA, Thorens B (2008) Increasing GLP-1-induced beta-cell proliferation by silencing the negative regulators of signaling cAMP response element modulator-alpha and DUSP14. Diabetes 57:584-593

43. Jansson D, Ng AC, Fu A, Depatie C, Al Azzabi M, Screaton RA (2008) Glucose controls CREB activity in islet cells via regulated phosphorylation of TORC2. Proc Natl Acad Sci U S A 105:10161-10166

44. Inada A, Hamamoto Y, Tsuura Y et al (2004) Overexpression of inducible cyclic AMP early repressor inhibits transactivation of genes and cell proliferation in pancreatic beta cells. Mol Cell Biol 24:2831-2841

45. Faruque OM, Le-Nguyen D, Lajoix AD et al (2009) Cell-permeable peptide-based disruption of endogenous PKA-AKAP complexes: a tool for studying the molecular roles of AKAP-mediated PKA subcellular anchoring. Am J Physiol Cell Physiol 296:C306-C316

46. Ramos LS, Zippin JH, Kamenetsky M, Buck J, Levin LR (2008) Glucose and GLP-1 stimulate cAMP production via distinct adenylyl cyclases in INS-1E insulinoma cells. J Gen Physiol 132:329-338

47. Moulder KL, Jiang X, Chang C et al (2008) A specific role for $\mathrm{Ca}^{2+}$-dependent adenylyl cyclases in recovery from adaptive presynaptic silencing. J Neurosci 28:5159-5168

48. Saxena R, Hivert MF, Langenberg C et al (2010) Genetic variation in GIPR influences the glucose and insulin responses to an oral glucose challenge. Nat Genet 42:142-148

49. Dupuis J, Langenberg C, Prokopenko I et al (2010) New genetic loci implicated in fasting glucose homeostasis and their impact on type 2 diabetes risk. Nat Genet 42:105-116

50. Rosengren AH, Jokubka R, Tojjar D et al (2010) Overexpression of alpha $\mathrm{a}_{2} \mathrm{~A}$-adrenergic receptors contributes to type 2 diabetes. Science 327:217-220 